\title{
Article
}

\section{Effects of an 8-Week Pre-seasonal Training on the Aerobic Fitness of Professional Soccer Players}

Michaelides, Marcos A, Parpa, Koulla M and Zacharia, Anthos I

Available at http://clok.uclan.ac.uk/29415/

Michaelides, Marcos A, Parpa, Koulla M and Zacharia, Anthos I (2019) Effects of an 8-Week Pre-seasonal Training on the Aerobic Fitness of Professional Soccer Players. Journal of strength and conditioning research. ISSN 10648011

It is advisable to refer to the publisher's version if you intend to cite from the work. http://dx.doi.org/10.1519/JSC.0000000000003209

For more information about UCLan's research in this area go to http://www.uclan.ac.uk/researchgroups/ and search for <name of research Group>.

For information about Research generally at UCLan please go to http://www.uclan.ac.uk/research/

All outputs in CLoK are protected by Intellectual Property Rights law, including Copyright law. Copyright, IPR and Moral Rights for the works on this site are retained by the individual authors and/or other copyright owners. Terms and conditions for use of this material are defined in the policies page.

\section{CLoK}

Central Lancashire online Knowledge www.clok.uclan.ac.uk

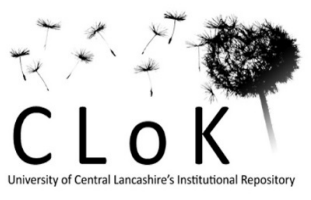


NUMBER 1 OF 1

\title{
AUTHOR QUERIES
}

\author{
DATE $\quad 5 / 18 / 2019$ \\ JOB NAME JSCR \\ ARTICLE JSCR-08-11789 \\ QUERIES FOR AUTHORS_ M.A. Michaelides et al.
}

\section{THIS QUERY FORM MUST BE RETURNED WITH ALL PROOFS FOR CORRECTIONS}

Please confirm the given names (pink) and surnames (blue) of authors have been identified correctly.

Please check and confirm whether all authors and their respective affiliations are appropriate.

AU1) Please check the edits made to the article title.

AU2) Please note that abstract and keywords have been taken from the provided PDF. Please check and correct if necessary.

AU3) Please confirm that the $p$-values are represented accurately and correct if necessary?

AU4) Please check and confirm the edits made to the sentence "The $\dot{V}_{O_{2}}$ at ventilatory threshold..."

AU5) Please confirm that this study was approved by an Institutional Review Board. Please also confirm the institution's name if not already stated.

AU6) Please provide the age ranges for all subjects mentioned in the Subjects section if you have not already. If any subjects were $<18$ years of age, please confirm that written parental consent was obtained. Please also confirm, if you have not already, that signed informed consent documents were obtained for all subjects.

AU7) Please clarify whether the height, weight, and age of subjects were measured as $\pm S D$ (standard deviation) or \pm SE (standard error).

AU8) Please provide manufacturer name. city for the product "Garmin wireless HR monitor."

AU9) Please note that as per the journal style, table and figure placements are not allowed in the "Discussion" section and hence have been introduced in the "Results" section. Please check and correct if necessary.

AU10) Please note that there is no in-text citation for Figures 1 and 2. Hence, please check the suggested in-text citation and correct the placement if necessary.

AU11) Please note that reference "17" is not cited in the text. Please cite it in the text or delete from the reference list. 


\title{
Effects of an 8-Week Pre-seasonal Training on the Aerobic Fitness of Professional Soccer Players
}

\author{
Marcos A. Michaelides, Koulla M. Parpa, and Anthos I. Zacharia \\ University of Central Lancashire, Pyla, Cyprus
}

\begin{abstract}
Michaelides, MA, Parpa, KM, and Zacharia, Al. Effects of an 8-week pre-seasonal training on the aerobic fitness of professional soccer players. J Strength Cond Res XX (X): 000-000, 2019-Pre-season in soccer training develops the physical requisites for competition and usually consists of a high volume of aerobic and anaerobic conditioning training including friendly games. The purpose of the study was to determine the effects of pre-season training on the aerobic fitness of professional soccer players. Nineteen professional male soccer players (age $=27.37 \pm 3.67$ years, height $=179.61 \pm 5.17 \mathrm{~cm}$, and body fat percentage $=11.3 \pm 3.19 \%$ ) participated in this study performed an incremental cardiopulmonary exercise testing on a treadmill before and after the 8 weeks of pre-season preparation. The results were analyzed using paired $t$ tests, revealing significant differences on several indices. The subjects improved significantly on maximal aerobic capacity $\left(\mathrm{V}_{2}\right.$ max $)$ and lasted significantly longer on the treadmill $(\infty<0.005)$. The $\dot{\mathrm{V}}_{2}$ at ventilatory threshold (VT) and respiratory compensation point (RCP) increased significantly $(0<0.005)$. The running velocity at ventilatory thresholds (VVT and VRCP) and at $\dot{\mathrm{V}}_{2} \max \left(\mathrm{VVO}_{2} \mathrm{max}\right)$ also increased significantly $(0<0.005)$. In conclusion, the results of this study, as expected, demonstrated that the proposed 8 weeks of pre-season training program was sufficient to cause significant improvements on the aerobic performance indices of professional soccer players. The study confirms the beneficial changes in the process of adaptations that occur with this type of training and can assist coaches and trainers in planning a successful pre-season training program.
\end{abstract}

Key Words: fitness testing in soccer, lactate threshold, pre-season training

\section{Introduction}

The pre-season training period in soccer aims at developing the physical requisites for competition. Unlike individual sports, soccer is characterized by a shorter pre-season training period and a longer competitive training period, especially when teams participate in international competitions (9). This requires careful strategic planning for training periodization because the pre-season training period consists of intense conditioning as well as a number of friendly games in addition to the technical and tactical practices that are concurrently scheduled (12). Consequently, the training load during the pre-season training period is higher than that of in-season training (20) and is expected to cause significant training adaptations on the aerobic system. Interestingly, recent studies $(10,18)$ demonstrated that when short intense running intervals (RIs), 30 seconds -4 minutes, are combined to the basic training volume, aerobic performance enhances significantly. Bangsbo (1) demonstrated that $90 \%$ of the total energy during a soccer game is supported by aerobic metabolism. Thus, the major aim of the preseason training period is to increase aerobic capacity that translates into increased running activity and decreased walking time during competitive soccer games (19). Helgerud et al. (14) demonstrated that maximal aerobic capacity $\left(\dot{\mathrm{V}}_{2} \mathrm{max}\right)$ enhancement leads to improved soccer performance, substantiated as increases in the distance covered, the level of work intensity, the number of sprints, and the number of involvements with the ball during competitive games. Although $\dot{\mathrm{V}}_{2}$ max fluctuates in professional soccer players $(4,5,13,15,24,27,38)$, those who compete at superior playing standards and championships demonstrate greater levels $(26,38)$.

Address correspondence to Dr. Marcos Michaelides, mmichaelides@uclan.ac.uk. Journal of Strength and Conditioning Research 00(00)/1-8

(c) 2019 National Strength and Conditioning Association
The greater $\dot{\mathrm{V}}_{2}$ max gain, however, is usually evident after a successful pre-season training program, specifically at the beginning of the competitive season $(15,27)$. The improvements observed are attributed to a higher aerobic contribution and the reduced involvement of the anaerobic energy system in energy expenditure (1). Evidently, running performance in endurance sports such as soccer is not only limited in high levels of $\dot{\mathrm{V}}_{2}$ max but also in other aerobic performance indices such as the lactate threshold (LT) and its associated running velocities (33). Thus, the purpose of this study was to examine the effect of the proposed 8-week pre-season training program on the aerobic performance indices of professional players.

\section{Methods}

\section{Experimental Approach to the Problem}

This experimental design used an 8-week pre-season training program to examine its effects on the aerobic fitness of professional soccer players participating at the highest standard of the Cyprus Soccer League. Before the 8 -week pre-season training period, the subjects went through cardiopulmonary exercise testing (CPET) on a motorized treadmill to determine their maximal aerobic capacity and its related indices. The results of the testing served to set up the training intensities for the RIs that were used during the 8-week pre-season period. On completion of the training program, the subjects were retested on the same protocol to examine the possible changes in their maximal aerobic capacity and adjust the training intensities for the in-season training modalities.

\section{Subjects}

Nineteen professional male soccer players (age $=27.37 \pm 3.67$ years, height $=179.61 \pm 5.17 \mathrm{~cm}$, and body fat percentage $=11.3$ $\pm 3.19 \%$ ) participated in this study. Participation in this study was 
Table 1

Overview of the 8-week pre-season daily type of training. *

\begin{tabular}{|c|c|c|c|c|c|c|c|}
\hline & Monday & Tuesday & Wednesday & Thursday & Friday & Saturday & Sunday \\
\hline \multicolumn{8}{|l|}{$\overline{W 1}$} \\
\hline AM & Off & Off & Off & Off & Off & Training & Off \\
\hline PM & Training & Training & Training & Training & Training & Off & \\
\hline \multicolumn{8}{|l|}{ W 2} \\
\hline AM & Off & Training & Off & Training & Training & Training & Off \\
\hline PM & Training & Training & Training & Training & Training & Off & \\
\hline \multicolumn{8}{|l|}{ W 3} \\
\hline $\mathrm{AM}$ & Training & Friendly game & Training & Off & Training & Friendly game & Off \\
\hline PM & Training & & Training & Training & Training & & \\
\hline \multicolumn{8}{|l|}{ W 4} \\
\hline AM & Training & Training & Friendly game & Training & Off & Training & Friendly game \\
\hline PM & Training & Training & & Training & Training & Training & \\
\hline \multicolumn{8}{|l|}{ W 5} \\
\hline AM & Off & Training & Friendly game & Off & Off & Friendly game & Off \\
\hline PM & Training & Training & & Training & Training & & \\
\hline \multicolumn{8}{|l|}{ W 6} \\
\hline AM & Off & Training & Friendly game & Off & Off & Off & Off \\
\hline PM & & Training & & Training & Training & Training & Training \\
\hline \multicolumn{8}{|l|}{ W 7} \\
\hline AM & Off & Friendly game & Off & Off & Off & Friendly game & Training \\
\hline PM & Training & & Training & Training & Training & & Off \\
\hline \multicolumn{8}{|l|}{ W 8} \\
\hline AM & Off & Off & Off & Off & Off & Official game & Training \\
\hline PM & & Training & Training & Training & Training & & Off \\
\hline
\end{tabular}

*W 1-8 = pre-season weeks; $\mathrm{AM}=$ morning training; PM = afternoon training.

voluntary, and all subjects were informed of the benefits and risks of the investigation before signing an institutionally approved informed consent document to participate in the study. Goalkeepers were excluded from the study because these players do not participate in the same type of training sessions as the in-field players. The study was approved by the University of Central Lancashire Science, Technology, Engineering, Medicine and Health (STEMH) ethics committee board and the Cyprus National Committee on Bioethics (CNCB). All measurements were obtained between the hours of 9:00 and 15:00. To mitigate the effects of the circadian rhythm on performance, the subjects were retested about the same time of the day.

\section{Procedures}

Cardiopulmonary Exercise Testing. The pre and post pre-season period CPET was performed on a motorized treadmill $(\mathrm{h} / \mathrm{p} /$
Cosmos Quasar med; H-P-Cosmos Sports \& Medical GmbH, Nussdorf-Traunstein, Germany). The gas exchange measurements were collected on the Cosmed Quark CPET (COSMED, Rome, Italy) system, using a breath-by-breath analysis through reusable rubber masks (model 7940; Hans Rudolph, Kansas City, MO, USA). The device was calibrated as suggested by the manufacturer. The laboratory temperature was kept constant at $20 \pm$ $2^{\circ} \mathrm{C}$, and the relative humidity was $50 \%$. The modified Heck incremental maximal protocol was used for the testing, as it was previously demonstrated to be valid and reliable on soccer players (34). The heart rate (HR) (Garmin wireless HR monitor; soft strap with ANT + sender, China) was continuously monitored.

Determination of Ventilatory Threshold and Respiratory Compensation Point. The ventilatory threshold (VT) and respiratory compensation point (RCP) were determined using different

Table 2

Training plan for weeks 1 and 2.

\begin{tabular}{|c|c|c|c|c|c|c|c|}
\hline & Monday & Tuesday & Wednesday & Thursday & Friday & Saturday & Sunday \\
\hline AM & Off & Off & Off & Off & Off & $\begin{array}{l}\text { Gym warm-up, circuit } \\
\text { training } 3 \text {, sets cool down }\end{array}$ & Off \\
\hline PM & $\begin{array}{l}\text { Warm-up, } 3 \text { runs } \times \\
\text { 1,200 m, passing drill, } \\
\text { rondo 8v2 }\end{array}$ & $\begin{array}{c}\text { Warm-up, } 3 \text { runs } \times \\
1,200 \text { m, passing control } \\
\text { drill, possession }\end{array}$ & $\begin{array}{c}\text { Warm-up, } 4 \text { runs } \times \\
1,000 \text { m, technique drill, } \\
\text { rondo }\end{array}$ & $\begin{array}{c}\text { Warm-up, } 4 \text { runs } \times \\
1,000 \mathrm{~m} \text {, technique drill, } \\
\text { rondo }\end{array}$ & $\begin{array}{l}\text { Warm-up, core training, } 5 \\
\text { runs } \times 900 \mathrm{~m} \text {, passing } \\
\text { drill, possession }\end{array}$ & Off & \\
\hline AM & Off & $\begin{array}{c}\text { 4-min running, dynamic } \\
\text { warm-up, } 6 \text { runs } \times \\
900 \mathrm{~m}\end{array}$ & Off & $\begin{array}{c}\text { 4-min running, dynamic } \\
\text { warm-up, } 7 \text { runs } \times \\
900 \mathrm{~m}\end{array}$ & $\begin{array}{c}\text { 4-min running, dynamic } \\
\text { warm-up, } 8 \text { runs } \times \\
900 \mathrm{~m}\end{array}$ & $\begin{array}{l}\text { Gym warm-up, circuit } \\
\text { training } 3 \text { sets, } \\
\text { coordination/sprint }\end{array}$ & Off \\
\hline PM & $\begin{array}{l}\text { Core training, 4-min } \\
\text { running, dynamic warm- } \\
\text { up, } 5 \text { runs } \times 1,000 \mathrm{~m} \text {, } \\
\text { passing drill, tactic } \\
\text { possession }\end{array}$ & $\begin{array}{l}\text { Gym warm-up, circuit } \\
\text { training } 3 \text { sets, } \\
\text { coordination, rondo, } \\
\text { possession, small game }\end{array}$ & $\begin{array}{l}\text { Core training, dynamic } \\
\text { warm-up, rondo, tactic/ } \\
\text { small-sided game, small } \\
\text { game }\end{array}$ & $\begin{array}{l}\text { Core training, dynamic } \\
\text { warm-up, rondo, tactic/ } \\
\text { technique, small-sided } \\
\text { game, small game }\end{array}$ & $\begin{array}{l}\text { Core training, dynamic } \\
\text { warm-up, rondo, small- } \\
\text { sided game, tactic game }\end{array}$ & Off & \\
\hline
\end{tabular}


Training plan for weeks 3 and 4.

\begin{tabular}{|c|c|c|c|c|c|c|c|}
\hline & Monday & Tuesday & Wednesday & Thursday & Friday & Saturday & Sunday \\
\hline$\overline{\mathrm{AM}}$ & $\begin{array}{c}\text { 4-min running, dynamic } \\
\text { warm-up, } 8 \text { runs } \times \\
600 \mathrm{~m}\end{array}$ & Friendly game & $\begin{array}{c}\text { 4-min running, dynamic } \\
\text { warm-up, } 8 \text { runs } \times \\
600 \mathrm{~m}\end{array}$ & Off & $\begin{array}{l}\text { 4-min running, dynamic } \\
\text { warm-up, } 4 \text { runs } \times \\
600 \mathrm{~m}, 4 \text { runs } \times 300 \mathrm{~m}\end{array}$ & Friendly game & Off \\
\hline PM & $\begin{array}{l}\text { Gym warm-up, circuit } \\
\text { training } 3 \text { sets, } \\
\text { coordination, rondo, } \\
\text { tactic game }\end{array}$ & & $\begin{array}{l}\text { Gym warm-up, circuit } \\
\text { training } 3 \text { sets, } \\
\text { coordination, passing } \\
\text { drill, possession, tactic } \\
\text { game }\end{array}$ & $\begin{array}{c}\text { Handball, small game, } \\
\text { rondo/football, funny } \\
\text { game }\end{array}$ & $\begin{array}{l}\text { Dynamic warm-up, } \\
\text { sprint, rondo, set pieces, } \\
\text { tactic game }\end{array}$ & & \\
\hline AM & $\begin{array}{c}\text { 4-min running, dynamic } \\
\text { warm-up, } 6 \text { runs } \times \\
300 \mathrm{~m}, 6 \text { runs } \times 200 \mathrm{~m} \\
\text { turn, } 6 \text { runs } \times 150 \mathrm{~m} \\
\text { turn }\end{array}$ & $\begin{array}{l}\text { Gym warm-up, field, } \\
\text { strength openings, } 10 \\
\text { runs } \times 40 \text { m turn }\end{array}$ & Friendly game & $\begin{array}{c}\text { 4-min running, dynamic } \\
\text { warm-up, } 8 \text { runs } \times \\
150 \text { m turn, } 8 \text { runs } \times \\
120 \text { m turn, } 8 \text { runs } \times \\
90 \text { m turn }\end{array}$ & Off & $\begin{array}{l}\text { 4-min running, dynamic } \\
\text { warm-up, } 10 \text { runs } \times \\
50 \mathrm{~m}, 8 \text { runs } \times 80 \mathrm{~m}, 6 \\
\text { runs } \times 100 \mathrm{~m} \text { turn, } 6 \\
\text { runs } \times 80 \mathrm{~m} \text { turn }\end{array}$ & $\begin{array}{c}\text { Friendly } \\
\text { game }\end{array}$ \\
\hline PM & $\begin{array}{l}\text { Dynamic warm-up, } \\
\text { rondo, possession, } \\
\text { transition, small-sided } \\
\text { game, tactic game }\end{array}$ & $\begin{array}{l}\text { Dynamic warm-up, } \\
\text { sprint, rondo, set pieces/ } \\
\text { finishing, tactic game }\end{array}$ & & $\begin{array}{c}\text { Dynamic warm-up, } \\
\text { plyometrics/elastic/ } \\
\text { coordination/finishing, } \\
\text { tactic possession, tactic } \\
\text { game }\end{array}$ & $\begin{array}{l}\text { Dynamic warm-up, } \\
\text { rondo, tactic, funny } \\
\text { games }\end{array}$ & $\begin{array}{l}\text { Dynamic warm-up, } \\
\text { sprint, rondo, tactic } \\
\text { game/set pieces }\end{array}$ & \\
\hline
\end{tabular}

criteria. The VT was determined through the V-Slope method, the point at which the increase in the rate of elimination of carbon dioxide $\left(\dot{\mathrm{V}}_{\mathrm{CO}_{2}}\right)$ is greater than the increase in $\dot{\mathrm{V}}_{2}$. The VT point was verified at the nadir of the $\mathrm{VE} / \mathrm{V}_{\mathrm{O}_{2}}$ curve. The RCP was determined at the nadir of the $\mathrm{VE} / \mathrm{V}_{\mathrm{CO}}$ curve $(2,37)$. The plots used for the determination of the thresholds utilized filtered breath-by-breath values (averaged into 10-second bins).

Pre-season Training Structure. A general overview of the 8-week [T1] pre-season program is presented in Table 1 and includes the categorization of the types of training as described by the coaching team. The pre-season period included 26 single training sessions, 12 double training sessions, 9 friendly games, and 6 rest days before the first official game. The detailed training modali[T2] ties during the 8-week pre-season period are presented in Tables $2-5$. The duration of morning training sessions (AM) was approximately 60 minutes, whereas the duration of afternoon training sessions was approximately 80-95 minutes.
Running Intervals. Weeks 1-5 consisted of several sessions of RI. The running distances covered are presented in Tables 2-4 in the form of number of runs $x$ distance in meters. The running intensity was individualized based on the initial pre-season period testing treadmill running speed at RCP and at $\dot{\mathrm{V}}_{2} \mathrm{max}$ (vRCP and $\mathrm{vVO}_{2} \mathrm{max}$ and max effort). Sprint interval training (SIT) included distances of up to $40 \mathrm{~m}$. High-intensity interval training (HIIT) was divided into 3 levels: (a) Intervals of 50-100 m were set at running speed based on the individual's $140 \%$ of vVO2max. (b) Intervals of $150-300 \mathrm{~m}$ were set at running speed based on the individual's $110 \%$ of $\mathrm{vVO}_{2} \max$. (c) Intervals between 300 and $600 \mathrm{~m}$ were set at running speeds based on the individual's $\mathrm{vVO}_{2} \mathrm{max}$. Tempo runs consisted of a running speed set on the individual's vRCP. The exercise-to-rest ratios (passive recovery) were set according to the guidelines provided by Iaia and Bangsbo (18) where max intensity bouts (2-10 seconds) received 50-100second rests, $70-100 \%$ of max speed bouts (10-40 seconds) received rest intervals of about 5 times the exercise duration, and

Table 4

Training plan for weeks 5 and 6.

\begin{tabular}{|c|c|c|c|c|c|c|c|}
\hline & Monday & Tuesday & Wednesday & Thursday & Friday & Saturday & Sunday \\
\hline$\overline{\mathrm{AM}}$ & Off & $\begin{array}{l}\text { Gym warm-up field, } \\
\text { strength openings, } 10 \text { runs } \\
\times 40 \mathrm{~m} \text { turn, } 8 \text { runs } \times \\
50 \mathrm{~m} \text { turn, } 6 \text { runs } \times 80 \mathrm{~m} \\
\text { turn }\end{array}$ & $\begin{array}{l}\text { Friendly } \\
\text { game }\end{array}$ & Off & Off & Friendly game & Off \\
\hline PM & $\begin{array}{l}\text { Mobility warm-up, passing } \\
\text { drill, rondo, starters } 60-\text { min } \\
\text { recovery, nonstarters } \\
\text { training }\end{array}$ & $\begin{array}{l}\text { Dynamic warm-up, rondo, } \\
\text { tactic game/set pieces }\end{array}$ & & $\begin{array}{l}\text { Mobility warm-up, passing } \\
\text { drill, rondo, starters } 60- \\
\text { min recovery, nonstarters } \\
\text { training, mobility warm-up }\end{array}$ & $\begin{array}{l}\text { Dynamic warm-up, rondo, } \\
\text { tactic game/set pieces }\end{array}$ & & \\
\hline $\mathrm{AM}$ & Off & $\begin{array}{c}\text { Gym, dynamic warm-up, } \\
\text { hurdles, strength running, } \\
\text { small-sided games, small } \\
\text { game }\end{array}$ & $\begin{array}{l}\text { Friendly } \\
\text { game }\end{array}$ & Off & Off & Off & Off \\
\hline PM & & $\begin{array}{l}\text { Dynamic warm-up, sprint, } \\
\text { rondo, tactic, set pieces }\end{array}$ & & $\begin{array}{l}\text { Starters recovery, } \\
\text { nonstarters training }\end{array}$ & $\begin{array}{l}\text { Passing warm-up, } \\
\text { passing, basket/handball, } \\
\text { funny, rondo }\end{array}$ & $\begin{array}{l}\text { Dynamic warm-up, } \\
\text { plyometric/elastic } \\
\text { coordination/finishing, } \\
\text { transition, tactic game }\end{array}$ & $\begin{array}{l}\text { Technique, } \\
\text { funny games }\end{array}$ \\
\hline
\end{tabular}




\section{Table 5}

Training plan for weeks 7 and 8.

\begin{tabular}{|c|c|c|c|c|c|c|c|}
\hline & Monday & Tuesday & Wednesday & Thursday & Friday & Saturday & Sunday \\
\hline AM & Off & Friendly game & Off & Off & Off & $\begin{array}{l}\text { Friendly } \\
\text { game }\end{array}$ & $\begin{array}{l}\text { Starters recovery, } \\
\text { nonstarters training }\end{array}$ \\
\hline PM & $\begin{array}{l}\text { Dynamic warm-up, sprint, } \\
\text { rondo, tactic game, set } \\
\text { pieces }\end{array}$ & & $\begin{array}{l}\text { Starters recovery, } \\
\text { nonstarters training }\end{array}$ & $\begin{array}{l}\text { Warm-up, rondo, } \\
\text { funny games, set } \\
\text { pieces }\end{array}$ & $\begin{array}{l}\text { Dynamic warm-up, sprint, } \\
\text { rondo, tactic game, set } \\
\text { pieces }\end{array}$ & & Off \\
\hline AM & Off & Off & Off & Off & Off & $\begin{array}{l}\text { Official } \\
\text { game }\end{array}$ & $\begin{array}{l}\text { Starters recovery, } \\
\text { rest players training }\end{array}$ \\
\hline PM & & $\begin{array}{l}\text { Gym, dynamic warm-up, } \\
\text { mobility, strength running, } \\
\text { small-sided games, small } \\
\text { game }\end{array}$ & $\begin{array}{l}\text { Dynamic warm-up, } \\
\text { plyometrics/elastic/ } \\
\text { coordination/finishing, } \\
\text { transition, tactic, tactic } \\
\text { game }\end{array}$ & $\begin{array}{l}\text { Technique, rondo, } \\
\text { funny games }\end{array}$ & $\begin{array}{l}\text { Dynamic warm-up, sprint, } \\
\text { rondo, set pieces }\end{array}$ & & Off \\
\hline
\end{tabular}

$50-100 \%$ of $\max$ speed bouts (5-90 seconds) received rest intervals of about 1-3 times the exercise duration. The intervals that indicate "turn" in Tables 3 and 4 included $180^{\circ}$ turns every $30 \mathrm{~m}$. The formula used to determine the time (seconds) needed to complete the intervals was $[3600 \times$ interval distance (meter)]/ [running speed $\left(\min \cdot \mathrm{h}^{-1}\right)$.

Other Types of Training Modalities During the Pre-season Training Period. Tables 2-5 summarize the different types of training modalities that took place during the 8 -week pre-season training period. The athletes typically performed 3 sets for each of the training modalities. The 4-minute runs (Tables 2-3) mostly consisted of pace runs to warm-up the players. The dynamic warm-up included dynamic stretching of the hip muscles followed by skipping ladder and passing drills. Hurdles was a type of plyometric training that included hopping over a series of 30- and 50-cm tall hurdles followed by short $10-\mathrm{m}$ sprints. The term strength running is an indicator of light running drills combined with agility sprints through cones or agility poles, with or without a ball. Rondos included small possession games in a restricted area allowing only one-touch passes while a smaller group of players (sometimes only one player) tried to gain possession (5 vs. 1,6 vs. 2 , and 9 vs. 3). Funny games were low- intensity drills that combined skills and collaborative work. These included juggling walks in teams, footvolley, and heading passing. In general, the purpose of these drills was to prevent the ball from touching the ground, allowing the subjects to work on their skills. The plyometrics/elastic/coordination/finishing included jumping up on 4 plyometric boxes $(30-45-60-75 \mathrm{~cm})$, followed by a run against resistance (68-kg resistance band-Acceleration trainer Stroops) in 3 directions (diagonal-forward-diagonal, $10 \mathrm{~m}$ each), then advancing through a series of agility poles (zig-zag direction), receiving a pass, and, finally, attempting to score a goal against a goalkeeper (1 vs. 1 ). Circuit training consisted of a series of exercises on 6 stations ( 3 sets of 30 -second efforts) that included body weight squats, push-ups, situps, supported lunches on a suspension trainer (TRX), 2-legged balances on a balance trainer (BOSU) and, finally, front isometric plunks. The term tactic in Tables 2-5 refers to small-sided games (SSGs) used by the coaching staff to prepare the plan for the friendly games. The time varied according to the coaching staff plans. Similar to tactic, small games were SSGs in a restricted playing area $(65 \mathrm{~m}$ long). The transition drills were also SSGs that typically included 3 color-coded teams. Their purpose was to develop the players' ability to quickly transition from defensive to attacking positions and vice versa. The players in one team followed the instructions of the

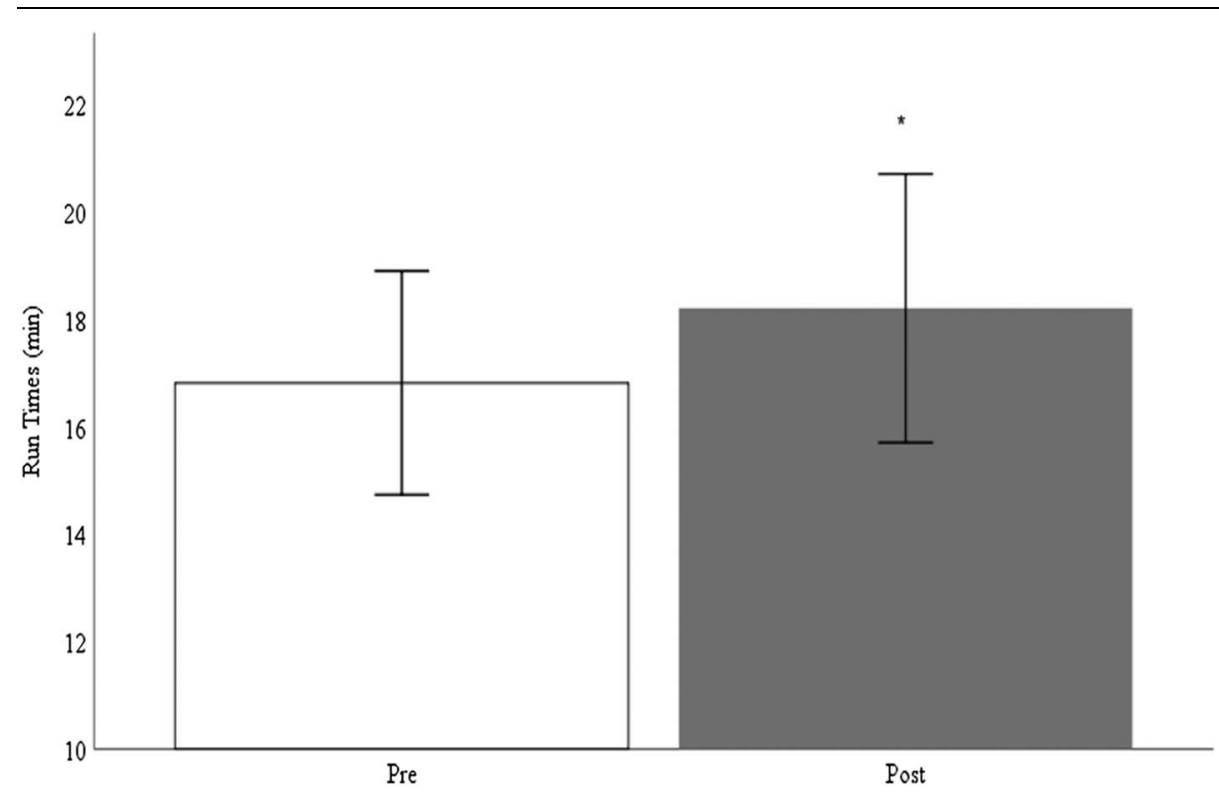

Figure 1. Mean run times before and after the pre-season training; ${ }^{*} p<0.001$; error bars are $S D$. 


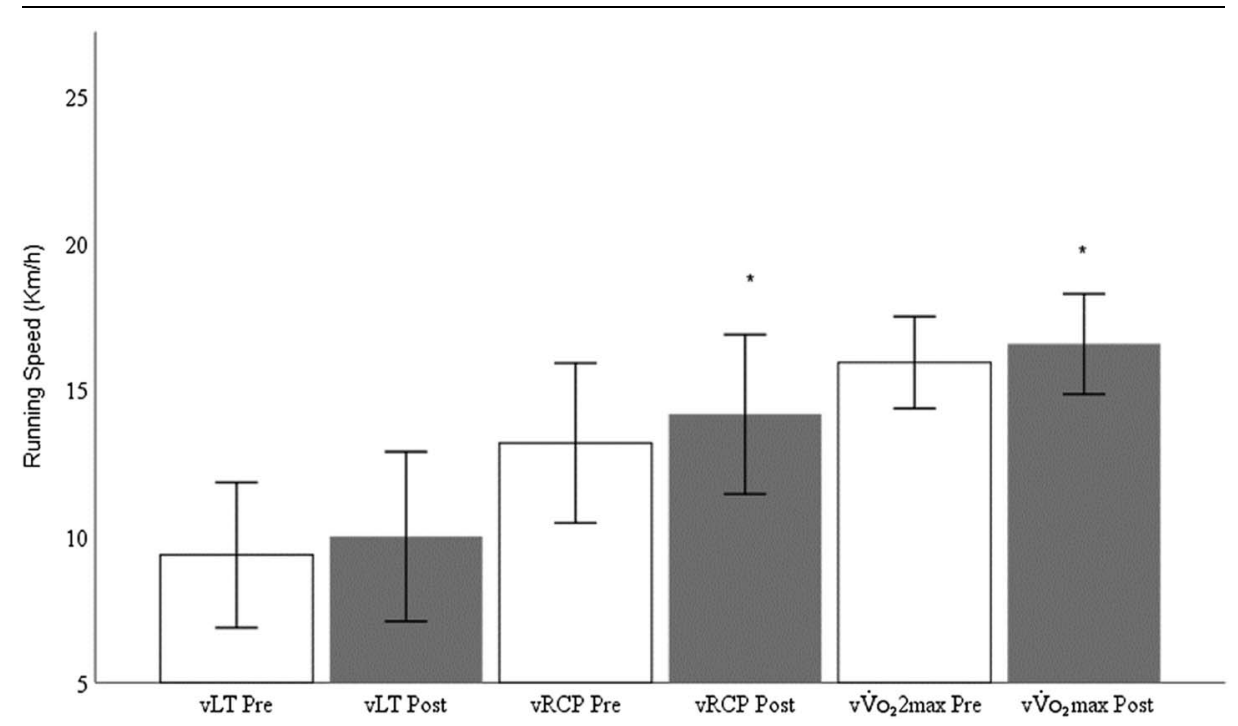

Figure 2. Running speeds before and after pre-season training at $L T, R C P$, and $\dot{V}_{2}$ max; ${ }^{*} p<0.001$; error bars are $S D . L T=$ lactate threshold; RCP = respiratory compensation point.

coaching staff to collaborate with another small group of players against a third group. The aforementioned high-intensity transition drills were repeated 3 times and lasted for about 3 minutes with 2minute rest intervals. The handball sessions were collaborative passing games. The players were restricted to passing the ball using their hands and score against another group of players only with a header.

\section{Statistical Analyses}

SPSS 25.0 for windows (SPSS, Inc., Chicago, IL, USA) was used for analyzing the results. Normality and homogeneity of variances were examined and verified using the Shapiro-Wilk and the Brown and Forsythe tests, respectively. The mean and SD were calculated for all parameters. Paired $t$-tests were used to examine the differences between the pre and post pre-season training period in both the anthropometric and aerobic fitness measures. Bonferroni adjustments were performed to avoid the inflation of getting at least one significant difference by chance. Thus, the level of significance was set at $p \leq 0.005\left(\mathrm{a}=0.05 \times 10^{-1}\right)$.

\section{Results}

The statistical analysis demonstrated that the subjects improved significantly in $\dot{\mathrm{V}}_{2} \max \left(t_{(18)}=-5.86, p<0.001\right)$, CI-95\% $=-4.60$ to $-1.58\left(\mathrm{ml} \cdot \mathrm{kg}^{-1} \cdot \mathrm{min}^{-1}\right) ; d=0.84$, and lasted significantly longer $\left(t_{(18)}\right.$ $=-8.69, p<0.001$ ), CI-95\% $=-1.85$ to -0.93 (minutes); $d=$ 1.21 , on the treadmill after the 8-week pre-season training.

Furthermore, the HR decreased slightly but not significantly at ventilatory thresholds (VT and RCP) and $\dot{\mathrm{V}}_{2} \mathrm{max}$ with values recorded after pre-season training at $141 \pm 15,170 \pm 9$, and 184 $\pm 8 \mathrm{~b} \cdot \mathrm{min}^{-1}$, respectively.

The running velocities at VT $(\mathrm{vVT})\left(t_{(18)}=-2.04, p<0.05\right)$, CI$95 \%=-1.52$ to $0.26\left(\mathrm{~km} \cdot \mathrm{h}^{-1}\right) ; d=0.47, \operatorname{RCP}(\mathrm{vRCP})\left(t_{(18)}=-4.87\right.$, $p<0.001)$, CI-95\% $=-1.57$ to $-0.40\left(\mathrm{~km} \cdot \mathrm{h}^{-1}\right) ; d=0.72$, and $\dot{\mathrm{VO}}_{2} \max \left(\mathrm{vVO}_{2} \max \right)\left(t_{(18)}=-4.47, p<0.001\right), \mathrm{CI}-95 \%=-1.04$ to $-0.23\left(\mathrm{~km} \cdot \mathrm{h}^{-1}\right) ; d=0.77$ increased significantly $(p<0.001)$.

The $\dot{\mathrm{VO}}_{2}\left(\mathrm{ml} \cdot \mathrm{kg}^{-1} \cdot \mathrm{min}^{-1}\right)$ at VT $\left(t_{(18)}=-3.78, p<0.001\right)$, CI$95 \%=-6.65$ to $-0.90 ; d=0.69$ and $\operatorname{RCP}\left(t_{(18)}=-3.66, p<\right.$ $0.001)$, CI- $95 \%=-7.17$ to $-0.86 ; d=0.79$ also increased significantly $(p=0.002)$ (Figures $1-3)$.

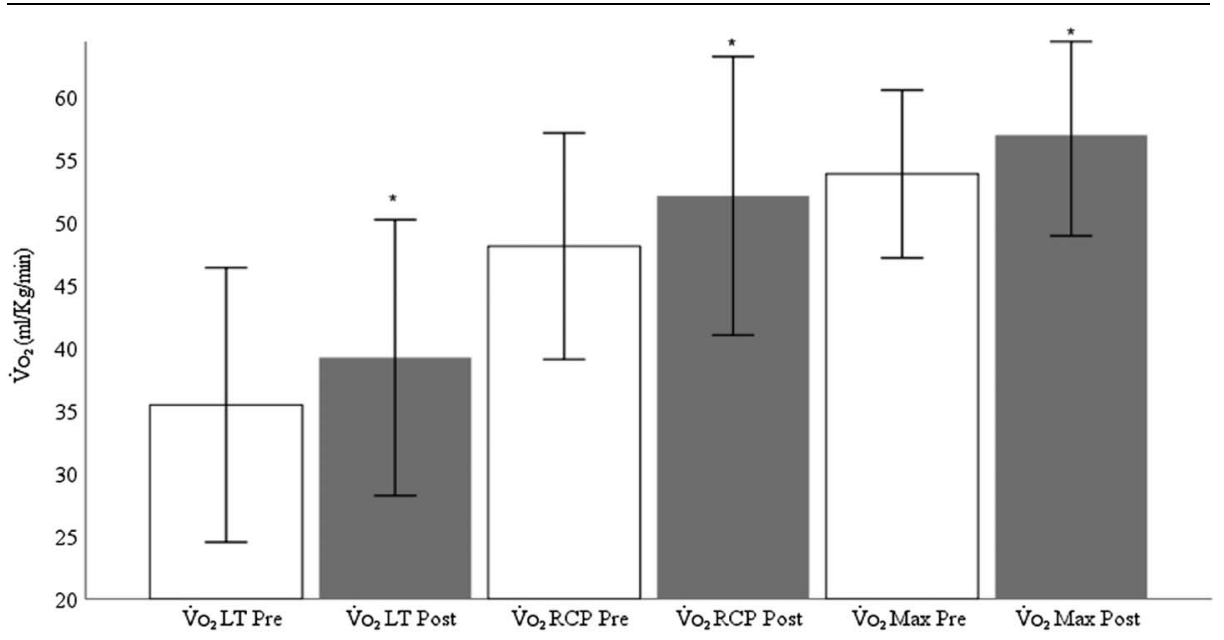

Figure 3. Oxygen consumption before and after pre-season training at $L T, R C P$, and $\dot{V}_{2}$ max; ${ }^{*} p<0.001$; error bars are $S D$. $L T=$ lactate threshold; $R C P=$ respiratory compensation point. 


\section{Discussion}

This study demonstrated that the proposed 8-week pre-season training program caused significant improvements on all the aerobic performance indices of the professional soccer players. The effects of pre-season training on the aerobic fitness indices of professional soccer players are rather unsystematic in the findings of previous research. Although some studies demonstrated marked increases in $\dot{\mathrm{V}}_{2}$ max after the pre-season training period $(15,21,27,28)$, others have shown minimal or no changes $(4,30,38)$. This inconsistency in the literature could be due to differences in scheduling and training philosophies across coaching teams, or due to a "ceiling effect," because higher standard, players are constantly on their maximal aerobic capacity, as suggested by Hoff et al. (16). The current study showed a significant improvement of about $6 \%$ in $\dot{\mathrm{V}}_{2} \max$ at the end of the 8 -week preparation period. This is an indication that the preseason exercise program of this study was effective in improving the aerobic fitness, with the increases reported to be similar to the ones reported previously $(19,21)$. Although $\dot{\mathrm{V}}_{2}$ max may provide a useful indication of the aerobic capacity of elite players (33), other aerobic performance indices, such as the LT, could be more sensitive to training than $\dot{\mathrm{V}}_{2}$ max. In sports with predominance in aerobic system contribution, LT might be a better indicator of aerobic endurance performance than $\dot{\mathrm{V}}_{2}$ max. Previous research demonstrated that LT (usually expressed as \% $\dot{\mathrm{V}}_{2} \mathrm{max}$ ) may continue to improve with training in relation to $\dot{\mathrm{V}}_{2} \mathrm{max}$, a process controlled by a different physiological mechanism (11). In addition, the VT of professional soccer players could be further enhanced without any significant change in $\dot{\mathrm{V}}_{2}$ max during the competitive season $(4,7)$. This is important for the fitness coaches because blood lactate accumulation and its associated ventilatory changes are common threshold concepts that are used for setting up training intensities $(3,25,29,36)$. In this study, the VT and RCP were detected at $65.63 \pm 9.97 \%$ and $88.26 \pm 5.88 \%$ of the $\dot{\mathrm{V}}_{2}$ max, respectively, before the pre-season training period. The 8 -week pre-season training in this study caused significant increases in both VTs. In particular, both the VT and RCP were detected at $67.88 \pm 7.29$ and $90.31 \pm 4.42 \%$ of the $\dot{\mathrm{V}}_{2} \max$ (Figure 3). The most common method for detecting and monitoring endurance characteristics is to determine the $\dot{\mathrm{V}}_{2}$ and running velocity at a fixed blood lactate concentration of 4 $\mathrm{mmol} \cdot \mathrm{L}^{-1}(21,40)$. The VT was previously found to coincide with the LT $\left(4 \mathrm{mmol} \cdot \mathrm{L}^{-1}\right)$ in soccer players, and both increased from about 80 to $86 \%$ of $\dot{\mathrm{V}}_{2} \max$ after the pre-season training period $(7,14)$. Although improvement in aerobic fitness coincides with reductions in HR response (39), the HR in this study demonstrated small but not significant decreases probably because of the short training period (11). In addition, vLT and $\mathrm{vVO}_{2}$ max were found to increase significantly after the pre-season training period (1). Ziogas et al. (40) demonstrated that soccer players of higher playing standards had a greater vLT on the commencement of the pre-season training period. In addition, Kalapotharakos et al. (21) pointed out the practicality of using the $\mathrm{vVO}_{2}$ max on assessing the aerobic demands of running and reported a $9.1 \%$ increase after the pre-season period. In this study, the running velocities $\mathrm{vVT}$, $\mathrm{vRCP}$, and $\mathrm{vVO}_{2}$ max were significantly improved after the pre-season training period by $6.76,7.50$, and $3.82 \%$, respectively. The pre-season training in this study resulted in the vVT and vRCP to occur at 60 and $86 \%$ of the $\mathrm{vVO}_{2}$ max, respectively, and that is typical for highly trained athletes (6). The vRCP detected at $13.17 \mathrm{~km} \cdot \mathrm{h}^{-1}$ before and increased significantly at $14.15 \mathrm{~km} \cdot \mathrm{h}^{-1}$ after the pre-season training period, whereas the $\mathrm{vVO}_{2}$ max also increased significantly from 15.92 to $16.55 \mathrm{~km} \cdot \mathrm{h}^{-1}$. Similar running velocities were reported by others $(4,14,21,34)$ after the pre-season training period. The beneficial effects of pre-season training on the running velocities at various thresholds can be of high importance. For instance, $\mathrm{vVO}_{2} \mathrm{max}$ in soccer has been found to positively correlate with the distance covered and the running intensity of professional soccer players (32). Furthermore, running speeds at maximum lactate steady state were found to improve the ability to use oxygen and, subsequently, to enhance metabolite removal (35).

Recent studies demonstrated that RIs such as high-intensity intermittent exercise training and speed endurance training drills improved the skeletal muscle oxidative capacity as well as exercise performance (10), and were superior to moderateintensity training organized as SSG (31). As it concerns the intervals performed in this study (Tables 2-4), exercise duration was reduced from week 1 to week 5 , whereas the intensity and the rest durations always increased in relation to the vRCP and $\mathrm{vVO}_{2} \max$ running speeds. The intensity and duration of the sessions were reduced during week 8 to prevent the development of a catabolic environment at the beginning of and during the competitive season (22). Combining RIs to soccer-specific training has a significant effect in aerobic fitness (about 7\% increase in $\dot{\mathrm{V}}_{2}$ max and LT) only 4 weeks into the pre-season training period (19). In addition, the combination of soccerspecific training with SIT may also provide further improvements during the in-season period. For instance, Ferrari Bravo et al. (8) observed 6 and $3 \%$ increase in $\dot{\mathrm{V}}_{2} \mathrm{max}$ and $\mathrm{RCP}$, respectively, using SIT twice a week $(3 \times 6$ maximal shuttle sprints of $40 \mathrm{~m}$ ), which was superior to HIIT (4 sets of 4 minutes at $90-95 \%$ of $\mathrm{HR}$ max with 3 minutes of active recovery at $60-70 \%$ of HR max).

Most studies highlight the importance of using thresholds to indicate and monitor the improvements in aerobic performance indices during each period of a typical soccer season $(21,40)$. In addition, they use specific exercise modalities, such as various types of interval training, embedded in the regular training to demonstrate further improvements $(10,31)$. This study aimed to present a complete spectrum of the pre-season training program including the RIs. The major limitation of the current study is the lack of training load for the remaining of the training modalities, as this requires GPS tracking devices. Thus, the contribution of the RIs used in this study vs. the rest of the training modalities on the demonstrated improvements of the aerobic performance indices is unknown. In addition, the use of RCP as the threshold is limited in the literature. The onset of RCP is depended on the hypoxic ventilatory chemosensitivity of the carotid bodies and the rate of lactic acid increase (37). Additive triggering mechanisms such as muscle afferents and other sensory inputs from exercising muscles have been proposed (29). However, the RCP's effectiveness as threshold for training intensity in sports is unknown and questionable (23).

In conclusion, the results of this study, as expected, demonstrated that the proposed 8 weeks of pre-season training program was sufficient to cause significant improvements on the aerobic performance indices of professional soccer players. The findings before the pre-season training period, along with the equivalent improvements, are in line with the aforementioned literature. The effectiveness of the proposed program on the aerobic performance indices was evident from the increases in the VT, RCP, and $\dot{\mathrm{V}}_{2}$ max presented in terms of $\% \dot{\mathrm{V}}_{\mathrm{O}_{2}}$ max and running speeds, respectively. The increases observed demonstrate physical preparedness and suggest that players will be able to afford improved 
pacing strategies and repeated sprint performance (also related to $\mathrm{vLT}$ and $\left.\mathrm{vVO}_{2} \mathrm{max}\right)$ during competitive games $(1,14,19,40)$.

\section{Practical Applications}

Physical fitness coaches should use the results from the physiological tests to monitor and adjust the training intensities of their players. Aerobic performance indices such as $\dot{\mathrm{V}}_{2}$ max, VT, and running velocities at the thresholds ( $\mathrm{vVT}$, $\mathrm{vRCP}$, and $\left.\mathrm{vVO}_{2} \mathrm{max}\right)$ are practical indicators to monitor aerobic performance. The proposed pre-season training caused significant improvements on the aerobic fitness that infers higher performance during the competitive season. Furthermore, the study demonstrated how a range of RIs divided into tempo runs, HIIT, and STI were used in combination to the various soccer-related training modalities to improve the aerobic fitness. In addition, the study provides useful information on how the running velocities were adjusted based on the vRCP and $\mathrm{vVO}_{2}$ max. Careful planning is needed to gradually increase the intensity of the intervals and adjust the volume to avoid injuries by including more soccer-related training such as SSG, technical-tactical drills, and participation to friendly games. Despite the fact that we are unable to isolate the contribution of the presented training modalities on the current improvements, the study can assist coaches and trainers in planning a successful pre-season training program.

\section{Acknowledgments}

The authors express their gratitude to the teams' coaching and medical staff as well as to the athletes for their cooperation and participation in this study. The authors have no conflict of interest with the nature of this study. This research received no funding.

\section{AU11 References}

1. Bangsbo J. Energy demands in competitive soccer. J Sports Sci 12: 5-12, 1994.

2. Beaver W, Wasserman K, Whipp B. A new method for detecting anaerobic threshold by gas exchange. J Appl Physiol 60: 2020-2027, 1986.

3. Binder RK, Wonisch M, Corra U, et al. Methodological approach to the first and second lactate threshold in incremental cardiopulmonary exercise testing. Eur J Cardiovasc Prev Rehabil 15: 726-734, 2008.

4. Casajús JA. Seasonal variation in fitness variables in professional soccer players. J Sports Med Phys Fitness 41: 463-469, 2001.

5. Clark NA, Edwards AM, Morton RH, Butterly RJ. Season-to-season variations of physiological fitness within a squad of professional male soccer players. J Sports Sci Med 7: 157-165, 2008.

6. Condello G, Reynolds E, Foster C, et al. A simplified approach for estimating the ventilatory and respiratory compensation thresholds. J Sports Sci Med 13: 309-314, 2014.

7. Edwards AM, Clark N, Macfayden AM. Lactate and ventilatory thresholds reflect the training status of professional soccer players where maximum aerobic power is unchanged. J Sports Sci Med 2: 23-29, 2003.

8. Ferrari Bravo D, Impellizzeri FM, Rampinini E, Castagna C, Bishop D, Wisloff. U Sprint vs interval training in football. Int J Sports Med 29: 668-674, 2008.

9. Francioni FM, Figueiredo AJ, Lupo C, Conte D, Capranica L, Tessitore A. Preseason strategies of Italian first league soccer clubs in relation to their championship ranking: A five-year analysis. J Hum Kinetics 50: 145-155, 2016.

10. Fransson D, Nielsen TS, Olsson K, et al. Skeletal muscle and performance adaptations to high-intensity training in elite male soccer players: Speed endurance runs versus small-sided game training. Eur J Appl Physiol 118: 111-121, 2018.

11. Gaesser GA, Poole DC, Gardner BP. Dissociation between VO2 max and ventilatory threshold responses to endurance training. Eur J Appl Physio 53: 242-247, 1984.
12. Gamble P. Periodization of training for team sports athletes. Strength Cond J 28: 56-66, 2006.

13. Haritonidis K, Koutlianos N, Koudi E, Haritonidou M, Deligiannis A. Seasonal variation of aerobic capacity in elite soccer, basketball and volleyball players. J Hum Mov Stud 16: 289-302, 2004.

14. Helgerud J, Engen LC, Wisloff U, Hoff J. Aerobic endurance training improves soccer performance. Med Sci Sports Exerc 33: 1925-1931, 2001.

15. Heller J, Prochazka L, Bunc V. Functional capacity in top league football players during the competitive season. J Sports Sci 10: 150, 1992.

16. Hoff J, Wisløff U, Engen LC, Kemi OJ, Helgerud J. Soccer specific aerobic endurance training. Br J Sports Med 36: 218-221, 2002.

17. Hoff J. Training and testing physical capacities for elite soccer players. J Sports Sci 23: 573-582, 2005.

18. Iaia FM, Bangsbo J. Speed endurance training is a powerful stimulus for physiological adaptations and performance improvements of athletes. Scand J Med Sci Sports 2: 11-23, 2010.

19. Impellizzeri FM, Marcora SM, Castagna C, et al. Physiological and performance effects of generic versus specific aerobic training in soccer players. Int J Sports Med 27: 483-492, 2006.

20. Jeong TS, Reilly T, Morton J, Bae SW, Drust B. Quantification of the physiological loading of one week of "pre-season" and one week of "inseason" training in professional soccer players. J Sports Sci 29: 1161-1166, 2011.

21. Kalapotharakos VI, Strimpakos N, Vithoulka I, Karvounidis C, Diamantopoulos K, Kapreli E. Physiological characteristics of elite professional soccer teams of different ranking. J Sports Med Phys Fitness 46: 515-519, 2006.

22. Kraemer WJ, French DN, Paxton NJ, et al. Changes in exercise performance and hormonal concentrations over a Big Ten soccer season in starters and nonstarters. J Strength Cond Res 18: 121-128, 2004.

23. Leo JA, Sabapathy S, Simmonds MJ, Cross TJ. The respiratory compensation point is not a valid surrogate for critical power. Med Sci Sports Exerc 49: 1452-1460, 2017.

24. Magal M, Smith RT, Dyer JJ, Hoffman JR. Seasonal variation in physical performance-related variables in male NCAA Division III soccer players. J Strength Cond Res 23: 2555-2559, 2009.

25. Mann T, Lamberts RP, Lambert MI. Methods of prescribing relative exercise intensity: Physiological and practical considerations. Sports Med 43: 613-625, 2013.

26. Marcos MA, Koulla PM, Anthos ZI. Preseason maximal aerobic power in professional soccer players among different divisions. J Strength Cond Res 32: 356-363, 2018.

27. Metaxas T, Koutlianos N, Sentelides T, Kouidi E, Deligiannis A. Physiological profile of amateur top-level soccer players according to positional role. J Hum Mov Stud 46: 347-358, 2004.

28. Metaxas T, Sendelides T, Koutlianos N, Mandroukas K. Seasonal variation of aerobic performance in soccer players according to positional role. J Sports Med Phys Fitness 46: 520-525, 2006.

29. Meyer T, Lucia A, Earnest CP, Kindermann W. A conceptual framework for performance diagnosis and training prescription from submaximal parameters-theory and application. Int J Sports Med 26: S38-S48, 2005.

30. Miller DK, Kieffer HS, Kemp HE, Torres SE. Off-season physiological profiles of elite National Collegiate Athletic Association Division III male soccer players. J Strength Cond Res 25: 1508-1513, 2011.

31. Mohr M, Krustrup P. Comparison between two types of anaerobic speed endurance training in competitive soccer players. J Hum Kinet 51: 183-192, 2016.

32. Rampinini E, Bishop D, Marcora SM, Ferrari Bravo D, Sassi R, Impellizzeri FM. Validity of simple field tests as indicators of match-related physical performance in top-level professional soccer players. Int J Sports Med 28: 228-235, 2007.

33. Reilly T, Bangsbo J, Franks A. Anthropometric and physiological predispositions for elite soccer. J Sports Sci 18: 669-683, 2000.

34. Santos-Silva P, Pedrinelli A, D’Andrea Greve J. Blood lactate and oxygen consumption in soccer players: Comparison between different positions on the field. MedicalExpress (Sao Paulo, Online) 4: M170102, 2017.

35. Silva JF, Dittrich N, Guglielmo LG. Aerobic evaluation in soccer. Revista Brasileira de Cineantropometria and Desempenho Humano 13: 384-391, 2011.

36. Skinner JS, McLellan TH. The transition from aerobic to anaerobic metabolism. Res Q Exerc Sport 51: 234-248, 1980. 
37. Takano N. Respiratory compensation point during incremental exercise as related to hypoxic ventilatory chemosensitivity and lactate increase in man. Jpn J Physiol 50: 449-455, 2000.

38. Tønnessen E, Hem E, Leirstein S, Haugen T, Seiler S. Maximal aerobic power characteristics of male professional soccer players, 1989-2012. Int J Sports Physiol Perform 8: 323-329, 2013.
39. Zavorsky GS. Evidence and possible mechanisms of altered maximum heart rate with endurance training and tapering. Sports Med 29: 13-26, 2000.

40. Ziogas GG, Patras KN, Stergiou N, Georgoulis AD. Velocity at lactate threshold and running economy must also be considered along with maximal oxygen uptake when testing elite soccer players during preseason. J Strength Cond Res 25: 414-419, 2011. 